\title{
Espécies novas de Eucerinae Neotropicais e notas sobre Dasyhalonia phaeoptera Moure \& Michener (Hymenoptera, Anthophoridae) ${ }^{1}$
}

\section{Danúncia Urban ${ }^{2}$}

\begin{abstract}
New species of neotropical Eucerinae and notes on Dasyhalonia phaeoptera Moure \& Michener (Hymenoptera, Anthophoridae). Lophothygater aculeata sp.n., Lophothygater nigrita sp.n. and Pachysvastra flavofasciata sp.n. are described and the diagnosis of the female of Dasyhalonia phaeoptera is given. KEY WORDS. Hymenoptera, Apoidea, Anthophoridae, Eucerinae, taxonomy
\end{abstract}

São descritas espécies novas de Lophothygater e Pachysvastra, dois gêneros descritos por MOURE \& MiCHENER (1955) e conhecidos somente pelas espéciestipo; e dadas a conhecer notas descritivas sobre a fêmea de Dasyhalonia phaeoptera Moure \& Michener, 1955, espécie conhecida anteriormente só pela descrição do macho. As medidas estão em milímetros e o material está depositado na Coleção de Entomologia Pe. J.S. Moure, Departamento de Zoologia, Universidade Federal do Paraná (DZUP).

\section{Pachysvastra flavofasciata sp.n.}

Fig. 1

Diagnose. Fêmea com faixa amarela no clípeo, pilosidade amarelada no dorso e lados do mesosoma, amarelo-fulva nas tíbias e basitarsos posteriores, enegrecida do segundo ao quarto tergo com faixas branco-pilosas densas nos flancos do terceiro e quarto.

Holótipo fêmea. Tegumento preto, clípeo com faixa amarela sub-marginal, a faixa não alcançando os cantos; mandíbulas com pequena mancha amarelo-acastanhada; tarsômeros castanhos; tégulas amarelo-acastanhadas; segundo ao quinto tergo com margem translúcida esbranquiçada e nos esternos a margem castanhoamarelada.

Pilosidade branca na cabeça, passando a amarelada no vértice, dorso do mesosoma, em grande parte dos mesepisternos e nos lobos pronotais; face ventral dos mesepisternos com cerdas castanhas lisas; castanho-amarelada nos artículos basais das pernas, com uma tonalidade ferrugínea nos trocanteres e base dos fêmures medianos; lado externo das tíbias anteriores e medianas ocráceo-pálido na base e castanho no ápice; nos tarsômeros anteriores castanho-escura e nos medianos castanho-amarelada; nas tíbias e basitarsos posteriores amarelo-fulva, as cerdas

1) Contribuição número 1063 do Departamento de Zoologia, Universidade Federal do Paraná.

2) Departamento de Zoologia, Universidade Federal do Paraná. Caixa Postal 19020, 81531-990 Curitiba, Paraná, Brasil. Bolsista do CNPq. 

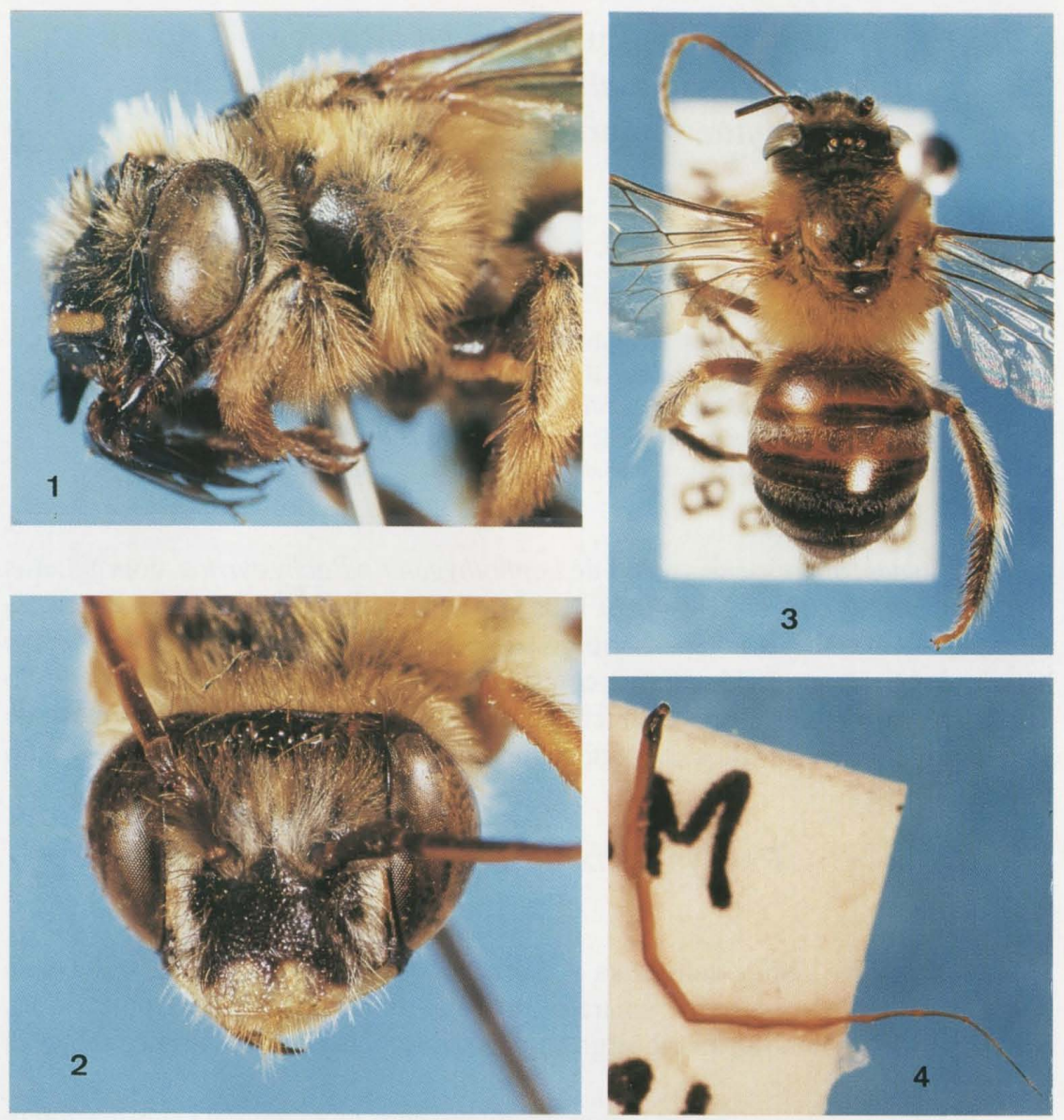

Fig 1-4. (1) Vista lateral da cabeça e mesosoma do holótipo de Pachysvastra flavofasciata sp.n.; (2) cabeça do holótipo de Lophothygater nigrita sp.n.; (3) vista dorsal; (4) flagelo do holótipo de Lophothygater aculeata sp.n..

castanhas no lado ventral dos basitarsos. Levemente amarelada e longa na base e disco do tergo basal, curta e até a margem nos flancos, no restante da margem também curta, porém enegrecida; do segundo ao quarto tergo curta e enegrecida na base deixando larga margem desprovida de pêlos, mais larga no meio e com poucos pêlos brancos subapicais nos cantos do segundo tergo; faixas látero-discais brancas fracamente arqueadas e afastadas da margem no terceiro e quarto tergos, maiores no quarto tergo; no quinto a pilosidade densa, castanho-clara no meio e fracamente amarelada nos lados; castanha no sexto tergo; amarelo-acastanhada nos esternos, passando a ocrácea nos flancos do segundo ao quarto onde forma tufos alongados, mais arruivada no quinto e castanha no sexto esterno. 
Premento e estípite com cerdas de ápice em gancho; base dos fêmures posteriores com pêlos longos enrolados e mesepisternos com cerdas lisas na face ventral. Tergo basal com pontuação densa, os intervalos igualando o diâmetro dos pontos; com depressões marginais largas no terceiro e quarto, e mais fracas no segundo tergo.

Comprimento 13,67; largura da cabeça 5,0; comprimento do olho 2,60; distância interorbital superior 3,17 e a inferior 2,75.

Holótipo fêmea. BRASIL, Paraná: [Palmeira], Papagaios Velhos, 6.I.1966, Pe. J.S. Moure leg. (DZUP).

Comentários. A espécie-tipo do gênero, Pachysvastra leucocephala (Bertoni \& Schrottky, 1910) difere pelo clípeo inteiramente preto, pilosidade preta no mesosoma, enegrecida nas tíbias e basitarsos posteriores; ocorre no centro-oeste e sudeste brasileiros, Cuiabá (Mato Grosso), Goiânia (Goiás), sul de Minas Gerais e Rio Claro (São Paulo).

Etimologia. O nome da espécie é alusivo à faixa amarela do clípeo.

\section{Lophothygater nigrita sp.n.}

\section{Fig. 2}

Diagnose. Macho com tegumento enegrecido nos tergos; antenas como em Lophothygater decorata (Smith, 1879) com os dois flagelômeros apicais quase do mesmo comprimento; projeção laminar dos trocanteres posteriores arredondada no ápice, não alargada no meio, fracamente retorcida e voltada para baixo e para o meio.

Holótipo macho. Tegumento preto, exceto: labro, metade basal das mandíbulas e faixa marginal do clípeo esbranquiçados, esta estreita nos flancos passando a larga e bilobada no disco; escapo, pedicelo e os três flagelômeros basais enegrecidos, restante do lado dorsal castanho-amarelado, porém no lado ventral os artículos mais claros desde o flagelômero basal; tégulas amarelo-acastanhadas; asas tingidas com amarelo e levemente acastanhadas para o ápice; pernas com os artículos basais castanho-escuros, nas anteriores e medianas até o ápice do fêmur somente no lado ventral e, nas posteriores o tegumento escuro também nos lados; tíbia e basitarso castanho-enegrecidos nas medianas e posteriores, restante das pernas amarelado com leve tonalidade acastanhada; tergos enegrecidos, com castanho na margem translúcida do primeiro e na área discal do segundo; esternos enegrecidos com áreas castanhas.

Pilosidade branca nas genas, paroculares inferiores e parte da fronte; amarelo-acastanhada no clípeo, restante da fronte, paroculares superiores e vértice; amarelo-fulva no mesosoma e branca no lado ventral dos mesepisternos e em parte das pernas, com cerdas enegrecidas de permeio na face posterior dos basitarsos medianos; basitarsos posteriores com cerdas enegrecidas longas dorsais; amarelada na face ventral dos tarsômeros. Levemente amarelada no tergo basal, muito curta, fina e esparsa na margem; do segundo ao quarto com faixa basal branca de pêlos curtos densamente ramificados; no quarto e quinto tergos os pêlos brancos mais 
longos e decumbentes formando faixa sub-marginal angulosa, mais estreita e mais afastada do ápice no meio, ultrapassando a margem só nos cantos do quinto tergo; margem do segundo e terceiro com pêlos finos castanhos, preta no sexto e sétimo tergos; flancos do terceiro ao quinto tergo com cerdas brancas, nos distais cerdas pretas; esbranquiçada e curta nos esternos, quarto e quinto com franja densa de pêlos decumbentes.

Quarto e quinto tergos com margem lisa, glabra e angulosa, no quinto mais larga que dois diâmetros de ocelo no meio.

Comprimento 11,67; comprimento da asa anterior 9,67; largura da cabeça 3,52; comprimento do olho 2,0; comprimento dos dois flagelômeros apicais 0,68 e 0,80 . basais.

Variações. Tergos enegrecidos ou com áreas amarelo-acastanhadas nos dois

Holótipo macho. BRASIL, Rondônia: Vilhena, 1.XII.1986, C.Elias leg. Parátipos: 5 machos com os mesmos dados do holótipo, 3 coletados em 20.X.1986, 1 em 11.XII.1986 e 1 em 27.XII.1986 (DZUP).

Comentário. O macho de Lophothygater decorata tem os tergos, tíbia e basitarso posteriores amarelo-méleos com manchas vagas castanhas nos primeiros; quarto tergo com margem lisa uniforme e estreita, no quinto a margem lisa pouco alargada no meio, como o diâmetro de um ocelo e, a projeção laminar dos trocanteres posteriores alargada no meio (URBAN 1967, fig. c). L. decorata ocorre no norte do BRASIL, desde Tefé, no Amazonas até a Serra do Navio, no Amapá.

Etimologia. Nome alusivo ao colorido dos tergos.

\section{Lophothygater aculeata sp.n.}

\section{Figs 3-4}

Diagnose. Macho com tegumento castanho e ferrugíneo nos tergos; antenas com o flagelômero distal filiforme e quase tão longo como o dobro do subapical (fig. 4); trocanteres posteriores com projeção laminar como em Lophothygater nigrita sp.n..

Holótipo macho. Preto, exceto: labro e metade basal das mandíbulas amarelo-esbranquiçados; clípeo com duas nódoas marginais esbranquiçadas muito estreitas no meio, afiladas e tingidas com amarelo nos lados; escapo, pedicelo e dois flagelômeros basais pretos, lado dorsal do terceiro ao quinto castanho e os demais amarelo-méleos, o distal enegrecido para o ápice. Tégulas amarelo-acastanhadas, translúcidas; asas amareladas, levemente acastanhadas para o ápice. Pernas pretas com os basitarsos castanho-escuros, os demais tarsômeros e as seguintes áreas amarelo-acastanhadas: face anterior dos fêmures anteriores, face posterior do fềmur e anterior da tíbia nas pernas medianas, face posterior do trocanter e do fêmur, e parte da face anterior dos fêmures posteriores; tíbias posteriores enegrecidas. Tergos castanhos, com larga margem translúcida também castanha; os dois basais com larga área ferrugínea, apical no primeiro e basal no segundo. Esternos com áreas ferrugíneo-acastanhadas e enegrecidas. 
Premento e estípite com cerdas de ápice em gancho; base dos fêmures posteriores com pêlos longos enrolados e mesepisternos com cerdas lisas na face ventral. Tergo basal com pontuação densa, os intervalos igualando o diâmetro dos pontos; com depressões marginais largas no terceiro e quarto, e mais fracas no segundo tergo.

Comprimento 13,67; largura da cabeça 5,0; comprimento do olho 2,60; distância interorbital superior 3,17 e a inferior 2,75.

Holótipo fêmea. BrasiL, Paraná: [Palmeira], Papagaios Velhos, 6.I.1966, Pe. J.S. Moure leg. (DZUP).

Comentários. A espécie-tipo do gênero, Pachysvastra leucocephala (Bertoni \& Schrottky, 1910) difere pelo clípeo inteiramente preto, pilosidade preta no mesosoma, enegrecida nas tíbias e basitarsos posteriores; ocorre no centro-oeste e sudeste brasileiros, Cuiabá (Mato Grosso), Goiânia (Goiás), sul de Minas Gerais e Rio Claro (São Paulo).

Etimologia. $\mathrm{O}$ nome da espécie é alusivo à faixa amarela do clípeo.

\section{Lophothygater nigrita sp.n.}

Fig. 2

Diagnose. Macho com tegumento enegrecido nos tergos; antenas como em Lophothygater decorata (Smith, 1879) com os dois flagelômeros apicais quase do mesmo comprimento; projeção laminar dos trocanteres posteriores arredondada no ápice, não alargada no meio, fracamente retorcida e voltada para baixo e para o meio.

Holótipo macho. Tegumento preto, exceto: labro, metade basal das mandíbulas e faixa marginal do clípeo esbranquiçados, esta estreita nos flancos passando a larga e bilobada no disco; escapo, pedicelo e os três flagelômeros basais enegrecidos, restante do lado dorsal castanho-amarelado, porém no lado ventral os artículos mais claros desde o flagelômero basal; tégulas amarelo-acastanhadas; asas tingidas com amarelo e levemente acastanhadas para o ápice; pernas com os artículos basais castanho-escuros, nas anteriores e medianas até o ápice do fêmur somente no lado ventral e, nas posteriores o tegumento escuro também nos lados; tíbia e basitarso castanho-enegrecidos nas medianas e posteriores, restante das pernas amarelado com leve tonalidade acastanhada; tergos enegrecidos, com castanho na margem translúcida do primeiro e na área discal do segundo; esternos enegrecidos com áreas castanhas.

Pilosidade branca nas genas, paroculares inferiores e parte da fronte; amarelo-acastanhada no clípeo, restante da fronte, paroculares superiores e vértice; amarelo-fulva no mesosoma e branca no lado ventral dos mesepisternos e em parte das pernas, com cerdas enegrecidas de permeio na face posterior dos basitarsos medianos; basitarsos posteriores com cerdas enegrecidas longas dorsais; amarelada na face ventral dos tarsômeros. Levemente amarelada no tergo basal, muito curta, fina e esparsa na margem; do segundo ao quarto com faixa basal branca de pêlos curtos densamente ramificados; no quarto e quinto tergos os pêlos brancos mais 
longos e decumbentes formando faixa sub-marginal angulosa, mais estreita e mais afastada do ápice no meio, ultrapassando a margem só nos cantos do quinto tergo; margem do segundo e terceiro com pêlos finos castanhos, preta no sexto e sétimo tergos; flancos do terceiro ao quinto tergo com cerdas brancas, nos distais cerdas pretas; esbranquiçada e curta nos esternos, quarto e quinto com franja densa de pêlos decumbentes.

Quarto e quinto tergos com margem lisa, glabra e angulosa, no quinto mais larga que dois diâmetros de ocelo no meio.

Comprimento 11,67; comprimento da asa anterior 9,67; largura da cabeça 3,52; comprimento do olho 2,0; comprimento dos dois flagelômeros apicais $0,68 \mathrm{e}$ 0,80 . basais.

Variações. Tergos enegrecidos ou com áreas amarelo-acastanhadas nos dois

Holótipo macho. BrasiL, Rondônia: Vilhena, 1.XII.1986, C.Elias leg. Parátipos: 5 machos com os mesmos dados do holótipo, 3 coletados em 20.X.1986, 1 em 11.XII.1986 e 1 em 27.XII.1986 (DZUP).

Comentário. O macho de Lophothygater decorata tem os tergos, tíbia e basitarso posteriores amarelo-méleos com manchas vagas castanhas nos primeiros; quarto tergo com margem lisa uniforme e estreita, no quinto a margem lisa pouco alargada no meio, como o diâmetro de um ocelo e, a projeção laminar dos trocanteres posteriores alargada no meio (URBAN 1967, fig. c). L. decorata ocorre no norte do BRASIL, desde Tefé, no Amazonas até a Serra do Navio, no Amapá.

Etimologia. Nome alusivo ao colorido dos tergos.

\section{Lophothygater aculeata sp.n.}

\section{Figs 3-4}

Diagnose. Macho com tegumento castanho e ferrugíneo nos tergos; antenas com o flagelômero distal filiforme e quase tão longo como o dobro do subapical (fig. 4); trocanteres posteriores com projeção laminar como em Lophothygater nigrita sp.n..

Holótipo macho. Preto, exceto: labro e metade basal das mandíbulas amarelo-esbranquiçados; clípeo com duas nódoas marginais esbranquiçadas muito estreitas no meio, afiladas e tingidas com amarelo nos lados; escapo, pedicelo e dois flagelômeros basais pretos, lado dorsal do terceiro ao quinto castanho e os demais amarelo-méleos, o distal enegrecido para o ápice. Tégulas amarelo-acastanhadas, translúcidas; asas amareladas, levemente acastanhadas para o ápice. Pernas pretas com os basitarsos castanho-escuros, os demais tarsômeros e as seguintes áreas amarelo-acastanhadas: face anterior dos fêmures anteriores, face posterior do fêmur e anterior da tíbia nas pernas medianas, face posterior do trocanter e do fêmur, e parte da face anterior dos fêmures posteriores; tíbias posteriores enegrecidas. Tergos castanhos, com larga margem translúcida também castanha; os dois basais com larga área ferrugínea, apical no primeiro e basal no segundo. Esternos com áreas ferrugíneo-acastanhadas e enegrecidas. 
Pilosidade amarelo-palha na cabeça, enegrecida nos cantos do clípeo, parte dorsal da fronte e no vértice; amarelo-fulva no mesosoma, esbranquiçada ventralmente; amarelo-palha nas pernas, com cerdas enegrecidas na face ventral dos basitarsos posteriores. Amarelo-fulva no tergo basal; faixa branca larga na base do segundo e terceiro tergos, os pêlos esparsos, plumosos e curtos; nos dois tergos seguintes com faixa branca discal, passando a subapical nos lados e deixando pequena área mediana glabra; no sexto e sétimo tergos castanhos; cerdas brancas nos lados do terceiro ao quinto e castanhas, de permeio, nos tergos distais; esbranquiçada nos esternos, com franja longa e decumbente no quarto e quinto.

Quarto tergo com margem lisa de largura uniforme, o quinto com a margem lisa e glabra angulosa no meio, onde iguala dois diâmetros de ocelo.

Comprimento 11,0; comprimento da asa anterior 9,67; largura da cabeça 4,0; comprimento do olho 2,12; comprimento dos dois flagelômeros apicais 0,64 e 1,36.

Holótipo macho. BrasiL, Amazonas: Beruri (rio Purus), 18.X.91, G.A.R. Melo leg. (DZUP).

Etimologia. Nome alusivo ao flagelômero distal longo e aculeado no macho.

\section{Dasyhalonia phaeoptera Moure \& Michener, 1955}

Diagnose da fềmea. Tegumento e pilosidade pretos, como no macho. Pêlos brancos só no lado externo nas tíbias posteriores; escopa tibial com pêlos simples, alguns plumosos, de permeio, na margem posterior; tergos com pêlos enegrecidos e grandes áreas glabras, o primeiro tergo com pêlos na base e nos lados, no restante quase glabro; do segundo ao quarto com faixas laterais decumbentes, afastadas da margem para o disco, pequenas no segundo e terceiro, e no quarto ocupando os terços laterais do tergo; quinto e sexto tergos denso-pilosos.

Coxas anteriores com pequeno espinho apical; pontuação densa na cabeça e mesosoma, esparsa e fina nos tergos; terceiro e quarto tergos com depressão marginal em ângulo obtuso bem aberto, quase até o meio, delimitada por linha irregular de pontos maiores, quinto tergo com pontuação densa.

Distribuição geográfica. BRASIL: São Paulo; PARAGUAI: Primavera.

\section{REFERÊNCIAS BIBLIOGRÁFICAS}

MOURE, J.S. \& C.D. MiCHENER. 1955. A contribution toward the classification of Neotropical Eucerini (Hymenoptera, Apoidea). Dusenia, Curitiba, 6 (6): 239331.

URBAN, D. 1967. O gênero Lophothygater Moure \& Michener, 1955 (Hymenoptera, Apoidea). Dusenia, Curitiba, 8 (5): 135-145.

Recebido em 17.IX.1998; aceito em 14.V.1999. 